\title{
Confianza y participación en México: ¿Dimensiones de la cooperación social y de la valoración del gobierno?
}

\author{
Rene Millán \\ Instituto de Investigaciones Sociales \\ Universidad Autónoma de México
}

\begin{abstract}
Resumo
O capital social - pela confiança, reciprocidade e conectividade social supostas - aumenta e agiliza as possibilidades de cooperação espontânea entre os indivíduos. Com o aumento da cooperação ocorreria um desempenho de governo mais eficiente. Este estudo analisa a complexa relação entre confiança e o desempenho institucional democrático em três cidades mexicanas. A partir do estudo de caso pergunta-se: Existe uma relação determinada entre confiança e desempenho institucional? Quais fatores fazem a mediação entre eles? Que tipo de relação se estabelece entre esses dois elementos fundamentais para a democracia? Que peso têm os outros componentes do capital social (reciprocidade, associativismo, etc) e que peso tem o contexto institucional nesta relação? Os dados sugerem que o capital social, particularmente seu componente de confiança, não se relaciona com uma maior eficiência governamental de forma direta. É plausível supor, em conseqüência, que se o capital social é indispensável para coordenar ações e facilitar a cooperação, sua eficácia coletiva e seu impacto no desempenho de governo estão também moldados por outro tipo de fatores tanto sociais como políticos ou institucionais.
\end{abstract}

Palavras-chave: capital social, confiança, desempenho governamental, México

\section{Resumen}

El capital social - por la confianza, reciprocidad y conectividad social que supone - aumenta y agiliza las posibilidades de cooperación espontánea entre los individuos. Al incrementarse la cooperación se haría más eficiente el desempeño de un gobierno. Este estudio analiza la compleja relación entre confianza y el desempeño institucional democrático en tres ciudades mexicanas. A partir de un estudio de caso se pregunta: ¿Existe una relación determinada entre confianza y desempeño institucional? ¿Qué tipo de relación se establece entre estos dos elementos fundamentales para la democracia?¿Qué factores median la relación entre confianza y desempeño institucional? ¿Qué peso tienen los otros componentes del capital social (reciprocidad, asociatividad, etc.) y qué peso tiene el contexto institucional en dicha relación? Los datos sugieren que el capital social, particularmente su componente confianza, no se relaciona con una mayor eficiencia del gobierno de manera directa. Es plausible suponer, en consecuencia, que si bien el capital social es indispensable para coordinar acciones y facilitar la cooperación, su eficacia colectiva y su impacto en el desempeño de gobierno están también moduladas por otro tipo de factores tanto sociales como políticos o institucionales.

Palabras-clave: capital social, confianza, desempeño de gobierno, México

\footnotetext{
1 Este artículo no hubiese sido posible sin la valiosa colaboración de Fiorella Mancini quien además de realizar los Cuadros hizo, como siempre, inteligentes y útiles comentarios.
} 


\section{Capital social y confianza: el problema de la cooperación}

Desde hace algunas décadas, y en particular a partir de los escritos de Coleman (1988), se ha desarrollado una amplia discusión en torno al Ilamado capital social. La discusión se he realizado, bajo muy distintas perspectivas, tanto en ámbitos estrictamente académicos como en aquellos relacionados con la formulación de políticas publicas (HOBSON, LEWIS y SIIM, 2001; DE SOUZA, 2000); con la gestión de administraciones gubernamentales (PUTNAM, 1994; VIVIEN, L y D. WILSON, 2001; SAMPSON; RAUNDENBUSH y EARL, 1997); con modelos de intervención de organismos internacionales (FOX y GERSHMAN, 2000; WOOLCOCK, 1998) ${ }^{2}$ o con la eficiencia de acciones colectivas de agentes específicos (OSTROM, 2000). La idea que subyace en el expandido uso del concepto de capital social es que su presencia genera capacidad social para coordinar acciones $\mathrm{y}$, en consecuencia, eleva las posibilidades de atender eficientemente problemas de distintos tipos, que van del desarrollo económico a la salud de ancianos. Se trata de problemas que serían difíciles de resolver eficientemente en ausencia de esas coordinaciones ${ }^{3}$. Por eso, en no pocas ocasiones se le ha considerado una alternativa conceptual y práctica, incluso para América Latina4.

Las sorprendentes "capacidades" del capital social están indisolublemente ligadas a los elementos a partir de los cuales se constituye. En la muy conocida, y ya clásica, definición de Putnam, Leonardi y Nanetti ${ }^{5}$ (1994) se establecen con claridad esos elementos: “El capital social - dicen - se refiere a las características de organización social, tales como la confianza, las normas y redes, que pueden mejorar la eficiencia de la sociedad mediante la facilitación de las acciones coordinadas" (p. 212, subrayado mío). Se entiende por normas, como se sabe, básicamente aquellas que refieren a la reciprocidad y por redes un sentido amplio de la dimensión asociativa, formal e informal; es decir, como conectividad social. En la definición misma ha quedado establecida una conexión entre confianza y

\footnotetext{
2 Desde 2003 el Banco Interamericano de Desarrollo ha impulsado la "Iniciativa Interamericana de Capital Social, Ética y Desarrollo" cuyo objetivo es "actuar como factor catalizador para impulsar las temáticas de ética, desarrollo y capital social por parte de gobiernos, partidos políticos, entidades empresariales, sindicatos, universidades, comunidades religiosas, organismos no gubernamentales y todas las instituciones que trabajen por el bienestar colectivo en las sociedades del continente". Por su parte, la publicación del Banco Mundial Expandiendo la medición de la Riqueza: indicadores de desarrollo ambiental sostenible, tiene como punto de partida el reconocimiento de que los activos de una país no se limitan a la riqueza mesurable en bienes "per capita" y resalta la importancia de la combinación de varias formas de capital, incluyendo el capital producto/físico, humano, natural y social.

3 "Al igual que otras formas de capital, el capital social es productivo y hace posible el logro de ciertos fines que serían inalcanzables en su ausencia." (COLEMAN, 1990, p. 304).

4 Incluso en América Latina se le ha considerado como un "nuevo paradigma" (ATRIA, 2003). Para otros trabajos en América Latina véase Durston (1999).

${ }^{5}$ De ahora en adelante citaré por economía ese texto clásico sólo como Putnam (1994).
} 
posibilidades (sociales) de efectuar acciones conjuntas y coordinadas. Una de las fortalezas del capital social es, entonces, que está asociado fuertemente a la confianza. Dentro y fuera de esa perspectiva, ella resulta un elemento clave cuando se analizan las posibilidades de elevar la eficiencia en la consecución de determinados fines sociales o colectivos. La confianza es importante ya que, por ejemplo:

- Reduce costos de transacción y monitoreo (NORTH, 1993)

- Facilita la administración de "bienes comunes" (OSTROM, 2000).

- Incrementa el rendimiento de asociaciones y organizaciones (STOLLE, 2001)

- Estructura y coordina mejor las expectativas (HARDIN, 2001).

- Eleva el desempeño de instituciones y de los gobiernos (PUTNAM, 1994)

No obstante estas distintas perspectivas, todas remiten a un mismo punto: la confianza es determinante en tanto propicia, facilita y da soporte a la cooperación. En sí misma, tiende a ser considerada el elemento clave que fortalece la capacidad de rendimiento social porque, más que cualquier otra variable, favorece, en efecto, las posibilidades de cooperación entre agentes e individuos. Por tanto, la cooperación resulta conceptualmente imprescindible porque viene a matizar el vínculo demasiado exigente entre confianza y coordinación (efectiva) de acciones que está implícito en el origen de la noción de capital social ${ }^{6}$. Sin embargo, no es generalmente aceptable que esa asociación se de forma directa o espontáneamente en cada caso, sin intervención de otros factores (BREHM y RAHN, 1997; STOLLE, 2001). No lo es, sobre todo, cuando teóricamente debe suponerse que la coordinación implica, por ser tal, una elevada eficacia en el logro de los objetivos y, por ello, desempeño o rendimiento social generalizado. En este sentido, E. Ostrom y T. K. Ahn (2003) han establecido que:

\begin{abstract}
"Identificamos tres formas amplias de capital social: 1) confianza y normas de reciprocidad, 2) redes y 3) reglas o instituciones formales e informales. Vemos la confianza como el concepto central que se ve afectado por las otras dos formas de capital social, así como por factores de contexto. Y la acción colectiva exitosa no puede explicarse sólo a partir del capital social. Otros factores contextuales también afectan los incentivos a los que se enfrentan los individuos y su probable comportamiento en escenarios de acción colectiva" (p. 158, subrayado mío).
\end{abstract}

\footnotetext{
6 "La cooperación voluntaria es más fácil en una comunidad que ha heredado un rico surtido de capital social...La cooperación espontánea es facilitada por el capital social” (PUTNAM, 1994, p. 211-213).
} 
Ostrom y Ahn insisten no sólo en la necesidad de distinguir, en tanto que no representan una identidad, entre confianza y logros de la acción colectiva (2003, p. 181-183), sino que establecen un esquema de incentivos que matizan o modulan los vínculos entre los componentes del capital social. Para ellas, confianza y normas de reciprocidad - que están en la base de la posibilidad de generar acciones colectivas - son variables que están sujetas a ser afectadas contextualmente y, en consecuencia, su eficacia para incentivar acciones puede variar. No obstante esa apreciación que es necesario tener en cuenta habría, en línea de principio, un vínculo entre instituciones/redes-confianza/reciprocidadlogros de la acción colectiva (OSTROM y AHN, 2003, p. 181). En términos netos, se trata de un Cuadro muy semejante al elaborado por Putnam: asociatividad (redes, grupos)-confianza/reciprocidad-coordinación de acciones.

Una diferencia central es, sin embargo, que para Ostrom su Cuadro se modula "externamente", por factores atendibles en el contexto y, en consecuencia, no sólo por las razones "internas" de la acción que los modelos racionalistas puros imputan. Por ello tienen más peso las instituciones. Para Putnam, en cambio, el Cuadro se regula por la cooperación (p. 217 y ss), elemento que es considerado "interno" al mismo vínculo de los elementos del capital social. Más precisamente: la cooperación estaría condicionada "externamente" por la cultura cívica ya que ella condensa la viabilidad práctica de aquella. La estrecha asociación conceptual entre cultura cívica y capital social induce a que la cooperación permanezca como un supuesto de ese vínculo; permanezca, de hecho, como una derivación teórica de la lógica "interna" de las interacciones de los componentes del capital social y su efectos culturales, cristalizados como práctica cívica. La cooperación como variable se encuentra normalmente subsumida en la confianza.

Pese a las diferencias, ambos Cuadros se asemejan en un punto que distingue a un gran número de estudios sobre el capital social: dan por sentado el vínculo o la asociación entre confianza y cooperación, si bien este rasgo está, por su construcción analítica, más acentuado en Putnam. "Los estudios sobre capital social - ha dicho Helffron (2001, p. 492) - ...han tratado de explicar su origen desde la perspectiva de la comunidad como determinante de las actitudes...a partir de la confianza y la cooperación... es decir como un a priori que les da sustento". Se supondría que ambas variables se mueven armónica y paralelamente. En un caso el "supuesto" ocurre porque se entiende que sólo contextualmente se modula la conexión entre confianza y cooperación; en otro, porque se asume que de cualquier forma, y en cualquier contexto, la asociación persiste sin que sea posible determinar como se regulan mutuamente y con qué variación. Por eso es que Stolle (2001) ha reprochado a Putnam y ha llamado la atención sobre la necesidad de examinar cómo los componentes del capital se relacionan, en especial aquellos 
MILLÁN, R. Confianza y paticipación en México....

elementos que se refieren a "membresía en asociaciones, confianza y actitudes de cooperación".

La cuestión es extraordinariamente importante porque en esas relaciones, Putnam basa su idea de que el capital social propicia un mejor desempeño de los gobiernos democráticos y una mejor valoración de los mismos. En un sentido determinante, la asociación entre capital social, desempeño y valoración positiva de los gobiernos, está anclada a la pregunta sobre si efectivamente la disposición a la cooperación "interpersonal”, que derivaría de la relación asociación/ confianza, se traduce "equivalentemente" en disposición a colaborar en asuntos públicos, o específicamente, con los gobiernos. En primera instancia, la cuestión remite a si la cooperación responde siempre a aquellos elementos y de manera semejante. En otros términos: no se trata sólo de constatar que cuando se da una cooperación voluntaria se está en presencia de interacciones de confianza, dato en cierto grado obvio, sino de identificar si la confianza incentiva la disposición anticipada de colaboración en el futuro, para eventos sociales que pueden presentarse mañana; y si, esa disposición se "generaliza" en la misma magnitud en que, en teoría, lo hace la confianza a partir de sus interacciones interpersonales que ocurren en la participación en asociaciones.

Es justo en ese doble "requerimiento" analítico que se ubica el interés de este trabajo: la asociación y la confianza generan un estándar similar de expectativas de cooperación? De ser el caso, esas se traducen homogéneamente en disposición de colaboración tanto en el ámbito de relaciones interpersonales como con los gobiernos? Existen factores que pueden regular o matizar el efecto de aquellos componentes del capital social en la disposición a la cooperación? Al hacer esa indagación, el trabajo la realiza bajo algunas consideraciones. Se asume, en principio, que la cooperación debe ser analizada sobre todo como "expectativa" - y no sólo como dato de un escenario efectivo de acción colectiva porque de esa forma adquiere peso analítico y se facilita apreciar con más fineza la disposición socialmente establecida para la colaboración en función de la participación en asociaciones y la confianza. En segundo lugar, se asume que los "incentivos" que esos dos últimos elementos pueden imprimir a la cooperación son variables. Además, la intensidad de la cooperación varía, aún manteniendo un mismo "stock" de participación y confianza, según con quién se requiera esa colaboración: los otros o el gobierno. Entendemos, entonces, que todo este Cuadro indica que existen factores que pueden modular la relación entre participación y confianza, por un lado, y cooperación, por el otro. Y que algunos factores son "internos" a las experiencias de cooperación y asociación. Lo que puede remitir a problemas de orden contextual o institucional para unos o de cultura cívica para otros. Finalmente, indagamos el comportamiento de esas variables en México y lo que se establece se acota en ese universo. 
Esa exploración se realiza con base en una encuesta sobre capital social ${ }^{7}$. La encuesta se aplicó en tres municipios mexicanos con distintas características a efecto de que fuese posible hacer comparaciones. Los tres municipios seleccionados fueron: Monterrey, Saltillo y Chilpancingo. En el contexto del país, ellos presentan las siguientes características: Monterrey, alto índice de desarrollo humano, baja marginalidad relativa y alta participación electoral. Saltillo, índice relativamente alto de desarrollo humano, baja marginalidad y baja participación electoral; Chilpancingo, bajo índice de desarrollo humano, alta marginalidad y baja participación electoral ${ }^{8}$. Este último municipio es notoriamente el más pobre de los tres y con menos desarrollo social y político. En términos generales han privado ahí, de manera más extensa que en los otros, lógicas clientelares y corporativas; vínculos horizontales más autoritarios y menos cívicos, para usar una descripción de Putnam. Por lo tanto, el contraste con este municipio es importante para valorar el comportamiento de las variables.

\section{Participación y confianza: relaciones con la cooperación}

Es un dato establecido, como hemos repetido, que la participación en asociaciones voluntarias es de vital importancia para los elementos constituyentes del capital social. Como se sabe, Putnam las ha dotado de una buena cantidad de atributos al considerarlas como fuentes de confianza y "escuelas" de cooperación. "La participación en organizaciones cívicas - ha dicho - inculca habilidades de cooperación así como sentido de responsabilidad compartida por los empeños públicos" (1994, p. 110) ${ }^{9}$. El número de contactos, y su permanente repetición ${ }^{10}$, que se dan en esas asociaciones genera confianza interpersonal. "El desarrollo de la confianza interpersonal y las experiencias de cooperación entre los miembros de las asociaciones tiende a ser generalizada hacia la sociedad" (1994, p. 111). Tenemos así que el paso de la confianza interpersonal, de la lógica cara a cara en el pequeño

\footnotetext{
7 La encuesta, de 3214 casos, fue realizada en el marco del proyecto "Capital social, incertidumbre y desempeño social", financiado por el Consejo Nacional de Ciencia y Tecnología y por la UNAM a través de su programa PAPIIT. La primera parte de ese proyecto fue realizada con la Dra. Sara Gordón y ha contado con la colaboración permanente de Fiorella Mancini.

${ }^{8}$ La participación electoral se tomó en referencia al año del levantamiento, y funciona como un indicador de desarrollo político.

9 "Las asociaciones voluntarias, continúa diciendo, son las más importantes formas de interacción horizontal y reciprocidad, que influyen en la interacción social y la cooperación entre actores." (p. 112).

${ }^{10}$ En términos de teoría de juegos el punto se plantea así: si el juego de la confianza se repite un número infinito de veces gracias a la intensidad de los contactos o, lo que es más realista, si ni A ni B saben cuándo se producirá una ronda final, entonces puede ocurrir que $A$ decida confiar en $B$ y que $B$, a su vez, confíe en A. Para un análisis sistematizado de la confianza desde la acción racional y la teoría de juegos (juego de la confianza de Kreps, estrategia tit-for-tat de Axelrod, etc.) véase Herreros Vázquez (2004).
} 
círculo, a la disposición generalizada de confianza, frente al otro genérico, presupone una diferencia sólo de escala: al expandirse ésta se expande en la misma proporción la disposición para la cooperación. Y esto nos conduce, en efecto, a uno de nuestros problemas.

Paralelamente a esa definición "espacial", conviene indicar - para efectos de los datos que se presentan - que la confianza ${ }^{11}$ puede ser entendida como una expectativa positiva sobre el comportamiento de los otros, en un marco donde el éxito de mi propio comportamiento depende del de los demás (DRASGUPTA, 1988). De esa forma, la confianza incorpora "interdependencia, incertidumbre y expectativa positiva” (LUNA y VELASCO, 2005, p. 129). La confianza (trust) se distingue conceptualmente de confidence (algo así como confiabilidad). La primera es para Hardin (2001, p. 15) "un conjunto de expectativas basadas en el entendimiento del interés del otro con respecto al mío", lo que supone "un interés encapsulado". La segunda, es una especie de expresión práctica de la primera, pero como tal se configura como resultado de un interés que es demarcado por un campo que reduce opciones, como en el caso de la "confianza por prestigio": "Yo puedo confiar en ti, no porque tenga una relación actual contigo, sino porque tú te relacionas con otros que pueden ser dañinos, al no establecer cierta confianza conmigo" (p. 19). La diferencia entre ambas, entonces, puede considerarse a partir de dos características: la confianza presupone incertidumbre y mayores posibilidades de elección en la interacción; confidence refiere a "una situación en la que el individuo toma un curso de acción sin considerar si hay otras opciones posibles" (LUNA y VELASCO, 2005, p. 130; véase también LUHMANN, 1996). La confiabilidad asume que las expectativas no serán defraudadas. Finalmente, la cooperación se distingue de la confianza no sólo conceptualmente sino en términos prácticos: la falta de aquella no implica la ausencia de la segunda. Y esa diferencia nos remite a otro tema de preocupación.

Bajo los sentidos anteriores, y en términos de exploración, acotamos la confianza a su posible generalización a un ámbito social determinado, es decir, delimitado espacial o simbólicamente. En este caso, usamos, por efectos de coherencia con otras mediciones que siguen, la referencia a la idea de "vecindario" o "colonia" porque es suficientemente acotada y, sin embargo, puede distinguirse claramente de otras agrupaciones de las cuales se esperaría un contacto más estrecho y continuo entre sus miembros (familia). Esa referencia, entonces, mantiene una escala apropiada de cercanía y generalización. Por ello, permite establecer también un "universo" acotado, a "mano" del individuo para identificar la percepción sobre las posibilidades de que la cooperación advenga. Como se apreciará en seguida, hablamos de expectativa (socialmente) generalizada de cooperación para indicar la credibilidad de que los otros tendrán un comportamiento de colaboración para

\footnotetext{
${ }^{11}$ De hecho es definida con múltiples sentidos. Para una buena síntesis véase: Luna y Velasco (2005).
} 
emprender un determinado objetivo común. Se asume en consecuencia, y como la teoría indica, que las expectativas de cooperación incrementan las posibilidades de coordinar acciones para la consecución de determinados fines (por ejemplo, exigir alumbrado o marchar por salario). Pero consideramos que esas expectativas pueden generalizarse, como veremos, totalmente o mayoritariamente. Esa distinción expresa una diferencia entre intensidad del compromiso que la expectativa comporta y la extensión del mismo.

A la luz de esta larga disquisición, conviene ahora ver si la confianza y la participación incentivan un mismo nivel de expectativas de colaboración de forma tal que entre ellas se puede sólo establecer una línea de continuidad para efectos del capital social o, si por el contrario, tiene impactos diferenciados. Comencemos con la participación como variable independiente.

Cuadro 1

Expectativas de cooperación y participación en asociaciones ${ }^{12}(\%)$

\begin{tabular}{|l|c|c|c|c|c|c|c|c|}
\hline \multirow{2}{*}{$\begin{array}{l}\text { Nivel de } \\
\text { expectativas }\end{array}$} & \multicolumn{2}{|c|}{ General } & \multicolumn{2}{c|}{ Chilpancingo } & \multicolumn{2}{c|}{ Saltillo } & \multicolumn{2}{c|}{ Monterrey } \\
\cline { 2 - 9 } & Participa & $\begin{array}{c}\text { No } \\
\text { participa }\end{array}$ & Participa & $\begin{array}{c}\text { No } \\
\text { participa }\end{array}$ & Participa $\begin{array}{c}\text { No } \\
\text { participa }\end{array}$ & Participa $\begin{array}{c}\text { No } \\
\text { participa }\end{array}$ \\
\hline Todos & 35,9 & 33 & 37,5 & 37 & 31,1 & 20,6 & 38,7 & 35,2 \\
\hline La mayoría & 41,7 & 41,4 & 37,8 & 31,4 & 44 & 52,5 & 41,3 & 39,9 \\
\hline Algunos & 21,5 & 23,5 & 22,4 & 29,7 & 23,6 & 24,8 & 19,7 & 22,8 \\
\hline Ninguno & 0,9 & 2,1 & 2,3 & 1,9 & 1,2 & 2 & 0,3 & 2,1 \\
\hline
\end{tabular}

Si nos atendemos a los supuestos típicos - particularmente en la línea de Putnam - deberíamos esperar que nuestros datos confirmaran con toda claridad una relación directamente proporcional entre participación en asociaciones y cooperación: mientras más se ejerce la primera, más extensa debería ser la disposición social a la segunda. El resultado, sin embargo, parece requerir de algún esfuerzo adicional de complejidad argumentativa. En términos gruesos, el Cuadro señala que, efectivamente, las expectativas de colaboración se incrementan para quienes participan en al menos una organización, asociación o grupo, lo que se revela al agregar los valores de las expectativas total y mayoritariamente generalizadas. Al mismo tiempo, los valores de las categorías bajas (algunos-ninguno) son sostenidamente más altos para los que no participan: éstos registran menos disposición social a la colaboración que los que si participan. El Cuadro también

\footnotetext{
${ }^{12}$ Estas asociaciones comprenden partidos, movimientos, ONGs, organizaciones religiosas, barriales, vecinales, grupos de jóvenes, clubs recreativos, etc.
} 
indica que es en el nivel de las expectativas totalmente generalizadas donde el "supuesto teórico" parece cumplirse de mejor manera: sus valores son siempre mayores al de los que no participan (incluido el caso de contraste: Chilpancingo). Sin embargo, es claro que esa es una expectativa altamente exigente (y en realidad poco probable). El hecho de que la "coherencia" de los supuestos se de sobre todo en ese nivel de exigencia y sólo en menor grado en los otros, es indicativo de que el incentivo a la cooperación que proviene de las organizaciones cívicas se da de forma diferenciada y no homogénea. Esto puede expresarse en términos de tipos de compromiso que las expectativas proyectan.

Si se consiente en que quien espera que los otros cooperen está obligado a actuar en consecuencia, es factible convenir también en que la totalmente generalizada indica la expectativa de un firme compromiso frente a los otros; manifiesta, es decir, una intensidad alta en la disposición a colaborar y por lo mismo de tipo no selectiva. Distinto es el problema de la extensión o proporción que esa expectativa alcanza. En contraste, el nivel de "mayoría" incorpora un grado menor de desilusión que el de "todos" e introduce un punto de serenidad en la exigente aspiración de una comunidad caracterizada por una cooperación tout court. Es en este sentido, que expresa la expectativa de un compromiso flexible, una disposición menos intensa y, por lo mismo, de tipo selectivo. La proporción de este compromiso - según los resultados del Cuadro - es más "extensa": mas gente la asume y en ello estabiliza sus expectativas. Su relación con la participación, sin embargo, resulta discretamente fluctuante y no se comporta con la misma consistencia, ni con el grado de coherencia que la totalmente generalizada. Por lo demás, los valores de ésta son sostenidamente menores (con excepción del caso de contraste)

En definitiva, la relación lineal entre participación y cooperación está establecida en el nivel de las expectativas más exigentes y menos selectivas. Estas tienen un comportamiento consistente con lo "supuestos" teóricos, pero resultan empíricamente menos "extensas". En cambio, las expectativas de un compromiso flexible y selectivo son más extendidas pero varían relativamente de la conexión esperada con la participación, no se manifiesta con claridad una asociación lineal entre ambas variables. De hecho, la relación entre participación y disposición social a la cooperación es más consistente y acotada en términos de compromiso firme-no selectivo pero más inconsistente y extenso en términos de compromiso flexibleselectivo. El "efecto" de generalización de expectativas de cooperación que la participación en asociaciones debería generar en las comunidades de referencia no es homogéneo. El efecto diferenciado advierte sobre la posibilidad de que las "cuotas de disposición a la cooperación" que se presentan como un capital en los círculos de interacción cercana, como son las asociaciones, no se generalicen en la misma proporción al resto de la sociedad o al ámbito público, al menos no con la misma intensidad de compromiso. Ya Stolle (2001) en su famoso estudio sobre los 
efectos de pertenencia en Suecia, Alemania y Estados Unidos, había encontrado que el desarrollo de la confianza y la colaboración se utiliza sólo en el contexto de los círculos y grupos, por lo que consideró esos recursos como "capital social privado". Nosotros asumimos algo distinto: no hay razón para presuponer que nada de ese capital se "transfiere" o se generalice en la sociedad porque los datos muestran valores importantes en la consistencia y la extensión. Pero tampoco es factible presumir que la experiencia del estar asociado, del participar en asociaciones "transfiere" o generaliza socialmente expectativas de cooperación en las "proporciones" teóricamente supuestas. Por ello, aunque es innegable que se da una relación positiva entre participación en asociaciones y cooperación, su "exportación" a ámbitos más amplios requiere de matices o de la consideración de que hay factores que previsiblemente la modulan.

En esta línea, una señal se advierte cuando desagregamos la información en términos del número de asociaciones en las que se participa; lo que puede expresar un rango de densidad asociativa.

Cuadro 2

Expectativas de cooperación y número de asociaciones (\%)

\begin{tabular}{|l|c|c|c|c|c|c|c|c|c|}
\hline \multirow{2}{*}{$\begin{array}{l}\text { Nivel de } \\
\text { expectativas }\end{array}$} & \multicolumn{3}{|c|}{ Chilpancingo } & \multicolumn{4}{c|}{ Saltillo } & \multicolumn{3}{c|}{ Monterrey } \\
\cline { 2 - 10 } & 0 & De 1 a 2 & 3 o más & 0 & De 1 a 2 & 3 o más & 0 & De 1 a 2 & 3 o más \\
\hline Todos & 37,4 & 37 & 38,4 & 22,4 & 31,4 & 29,7 & 35,3 & 37,6 & 45,8 \\
\hline La mayoría & 31,1 & 36,9 & 39,6 & 50,3 & 44,2 & 43,1 & 41,3 & 43 & 29,7 \\
\hline Algunos & 30 & 23,7 & 19,8 & 25,1 & 22,9 & 26,8 & 21,6 & 19 & 24,4 \\
\hline Ninguno & 1,5 & 2,4 & 2,2 & 2,2 & 1,4 & 0,4 & 1,9 & 0,4 & \\
\hline
\end{tabular}

En conjunto, estos resultados no niegan pero si plantean algunas dudas en torno a la capacidad lineal de la densidad de la participación, o del asociarse, para incentivar expectativas de cooperación. En primer término, no parece ser posible asentar que priva una relación directa, automática, entre el número de asociaciones en las que se participa y el aumento en las expectativas de colaboración. La relación se da consistentemente sólo en un caso en el nivel de la expectativa mayoritaria (Chilpancingo) y en otro más (Monterrey) en el nivel de la totalmente generalizada. Las expectativas de cooperación no se incrementan de manera lineal con la densidad y variedad de la participación. En segundo lugar, si se agregan las expectativas total y mayoritariamente, es interesante notar que es más consistente la relación entre densidad de la asociación y la cooperación cuando se mantiene una participación moderada (entre una o dos). En tercer lugar, al sostener esa misma agregación, se revela que en dos de los tres casos las expectativas de 
cooperación de los que participan en tres o más asociaciones son semejantes a las que mantienen los que no participan en ninguna. En consecuencia, el efecto de "incentivo" de la participación diferenciada, diversificada, se diluye o se pierde.

El único caso donde ese efecto no se pierde, sino que confirma la relación positiva, es paradójicamente el de contraste (Chilpancingo) que está caracterizado, en términos comparativos, por una cultura de relaciones más jerárquicas y corporativas. Persiste en este caso una cierta obligatoriedad social que incentiva la pertenencia a las asociaciones. Tiene, además, el índice más alto de asociacionismo: casi la mitad de la población participa en algún tipo de grupo o asociación frente a un tercio de los otros dos casos (según datos de la encuesta). En conjunto, tenemos entonces un doble perfil en la densidad asociativa. De un lado, la "obligatoriedad" del asociacionismo parece conducir a que se fortalezca el incentivo cooperativo de la participación pero al mismo tiempo, como Putnam ha indicado, ese incentivo se pierde en el ámbito de la actividad cívica si las asociaciones son "implantadas" (1994, p. 111-112). Y como veremos más adelante, efectivamente en este caso se registra la relación más débil entre confianza y cooperación con los otros, entre ciudadanos o vecinos. Del otro lado, en lo dos casos restantes, el asociacionismo parece producir un efecto "nulo" en las expectativas de cooperación después de un cierto límite: en ese supuesto, no existiría la posibilidad de garantizar un incentivo sostenido a la cooperación frente a un incremento, por así decirlo, infinito del asociarse o del participar. El punto es relevante porque plantea la cuestión de bajo qué condiciones, y en qué tipo de comunidad, el estar multiasociado podría bloquear o reducir las posibilidades de extender el beneficio público de la disposición a cooperar ${ }^{13}$. Donde, en definitiva, la densidad del asociacionismo afecta negativa o positivamente las expectativas de colaboración, dado que si parece estar en grado de modular esa vinculación.

Comparativamente, la cooperación mantiene una relación más directa con la confianza que con la participación en asociaciones. Así se advierte cuando se constata que los que no tienen confianza tienen sostenidamente una baja expectativa de cooperación, tanto en el nivel de la total como de la mayoritariamente generalizada. A diferencia de la participación, la relación positiva entre confianza y cooperación se da - para usar la misma clasificación - tanto en términos de intensidad como de extensión, es decir, se presenta tanto en términos de expectativa de un compromiso firme-no selectivo como de uno flexible-selectivo. Bajo el

\footnotetext{
${ }^{13} Y$ a algunos autores han indicado el síndrome de "disociación" que propicia la expansión exagerada del asociacionismo: "...la frecuencia y la intensidad creciente de los fenómenos de disociación - ha dicho uno de ellos. no son ni un singular accidente, ni un costo inevitable del desarrollo sociocultural, ni un hecho estadístico (ante más asociaciones tanto más disociación), ...sino un efecto perverso de la difusión misma de los procesos de asociación en una sociedad...diferenciada..." (GALLINO, 1981, p. 24). Diferenciada significa, simplemente, compleja: menos comunitaria.
} 
razonamiento anterior, el dato lleva a admitir que es más factible que los incentivos cooperativos de la confianza trasciendan los círculos asociativos en mayor medida que los de la mera participación. El Cuadro parece confirmar que la participación en asociaciones, por sí misma, no tiene un impacto similar al de la confianza en la conformación de expectativas de cooperación. Y, en consecuencia, la confianza no es un derivado exclusivo de la participación. Es decir, la base de su generalización social parece estar - como quiere Putnam - sólo en el asociarse cívicamente. Brehm y Rahn (1977) constataron, sin bien en otro contexto, que no existía relación directa y simétrica entre esas dos últimas variables. Para ellos, la participación cívica incentivaba en algún grado la confianza, pero ésta no incentivaba en igual medida aquella. En nuestro contexto, como veremos, la participación genera confianza pero sobre todo otro tipo de insumos.

Cuadro 3

Expectativas de cooperación y confianza interpersonal (\%)

\begin{tabular}{|l|c|c|c|c|c|c|c|c|}
\hline \multirow{2}{*}{$\begin{array}{l}\text { Nivel de } \\
\text { expectativas }\end{array}$} & \multicolumn{2}{|c|}{ General } & \multicolumn{2}{c|}{ Chilpancingo } & \multicolumn{2}{c|}{ Saltillo } & \multicolumn{2}{c|}{ Monterrey } \\
\cline { 2 - 9 } & Confía & No confía & \multicolumn{1}{c|}{ Confía } & No confía & \multicolumn{2}{c|}{ Confía } & No confía & \multicolumn{2}{c|}{ Confía } & No confía \\
\hline Todos & 37,5 & 30,8 & 43,4 & 30,5 & 30,7 & 23,4 & 39,2 & 34,3 \\
\hline La mayoría & 44,3 & 41,7 & 34,6 & 33,3 & 51,4 & 46,2 & 43,4 & 40,4 \\
\hline Algunos & 17 & 25,6 & 20,4 & 33,9 & 16,6 & 28,3 & 16,3 & 23,5 \\
\hline Ninguno & 1,2 & 1,9 & 1,6 & 2,3 & 1,3 & 2,2 & 1,1 & 1,7 \\
\hline
\end{tabular}

Como sea, entre confianza y expectativas de colaboración si se da con toda claridad una relación positiva y así establece el comportamiento en todos los municipios ${ }^{14}$. La proposición de que aquellos que confían tienen más expectativas de cooperación se confirma, sin variación sustantiva, independientemente de las características especificas de la comunidad, sean esas una cultura cívica conformada o incipiente, o mejores niveles de integración o desarrollo. En efecto, el tipo de relación positiva entre ambas variables persiste sin considerar los contextos pero hay aspectos que sugieren que, sin alterarla, la modulan. Hay un aspecto que debería notarse. Sólo en el caso de contraste (Chilpancingo), la expectativa de colaboración totalmente generalizada tiene una proporción superior a la que registra la mayoría $(43,4 \%$ - 34,6\%). Además, el mismo dato se registra en la relación con la participación (Cuadro 1: 37,5\% - 37,8\%). De conformidad con lo que la totalmente generalizada representa, este caso tendría la expectativa más sólida de un

\footnotetext{
14 Debido a la selección y tamaño de la muestra cada municipio puede ser analizado como dominio de estudio.
} 
compromiso firme-no selectivo: una gran disposición a la colaboración. El elemento desconcertante es que simultáneamente se caracteriza por mostrar la asociación más débil entre confianza interpersonal y expectativas de cooperación, si se suman la total y mayoritariamente generalizada. La cuestión es importante porque señalaría de nuevo una paradoja aparente. En la sociedad que presenta una situación de marginalidad más aguda y un ambiente de clientelas, la intensidad y la extensión del compromiso tenderían a coincidir más plenamente que en los otros casos.

Una explicación más o menos plausible es que en el caso de contraste (Chilpancingo) una cultura cívica menguada ejercería un control social fuerte apoyada en comportamientos acentuadamente comunitarios. Ambas condiciones - comunidad y control - actuarían de forma contextual en la formación de expectativas; o más precisamente: reforzando el vínculo entre confianza y cooperación a través de una marcada exigencia de compromiso firme-no selectivo. Pero el mantenimiento de esa exigencia, en tanto que no corresponde a la confianza entre la gente, debe darse mediante formas específicas de autoridad. Coleman sostuvo que la autoridad constituye un tipo de capital social porque su presencia garantiza que la consecución de fines comunes esté basada en expectativas más estables (1990) ${ }^{15}$. Desde luego, la autoridad como capital social es de primera importancia cuando las expectativas de cooperación, aunque exigentes, pueden ser frágiles porque dicha exigencia no se corresponde con los niveles de confianza interpersonal de la comunidad. Si esa condición existe, como parece ser el caso, es muy probable que se verifique que la autoridad se realice a través de una sólida presencia de instituciones públicas como factores que estructuran relaciones entre la gente, bajo modalidades específicas de intercambio.

De ser así, se tendría - en principio - una enorme disponibilidad social para coordinar o llevar a cabo acciones colectivas y, previsiblemente, para alcanzar sus objetivos (en lo términos de Ostrom). Pero no necesariamente se tendría una mejor cultura democrática o un mejor rendimiento institucional (en los términos de Putnam). La diferencia, en último análisis, estribaría en si se cuenta con una colaboración social más autorregulada, lo que no niega la incorporación de instituciones públicas de ninguna manera, o una cooperación más dirigida. En consecuencia, la idea de "cultura cívica" (y política) parece volverse importante ${ }^{16} \mathrm{o}$,

\footnotetext{
15 Dos razones hace que I autoridad sea una forma de capital social: la primera porque ella representa que "un actor cede sus derechos de control sobre determinadas acciones a otro" de manera que se estructura una relación. La segunda razón refiere al servicio que presta: "no es sólo dar orden a las tareas, sino favorecer que todos contribuyan al beneficio colectivo y reducir el problema del gorrón (freerider)". Véase: René Millan y Sara Gordón (2004, p. 719).

16 La diferencia entre cultura cívica y clientelismo hace que el carácter de la participación varíe "porque la naturaleza de la política es bastante diferente. El comportamiento político da por sentado en algunas regiones que la política se refiere a la deliberación de los asuntos públicos. Por el contrario, en otras
} 
en otra línea, el problema de la dimensión democrática de los contextos institucionales: porque ambos parecen modular la confianza y la cooperación. Pero admitir ese efecto de la "cultura cívica" no equivale a concordar con la afirmación de que, por sí misma, "la confianza permite que se supere el oportunismo" (PUTNAM, 1994, p. 109) o el clientelismo. En el marco de este estudio, la cuestión, en definitiva, se plantea de otra manera: la cultura cívica no determina la relación positiva entre confianza y expectativas de cooperación, pues ésa se da bajo otras pautas, simplemente modula su solvencia en las interacciones entre los individuos, y en las posibilidades de que esa solvencia se transmita a otros objetos de colaboración pública bajo pautas más democráticas. Pero ello implica que la confianza, y la cooperación a ella asociada, sea una función directa o exclusiva de la cultura cívica. La idea de Ostrom de que la "confianza" es un elemento modulado contextualmente cobra fuerza en el caso de contraste.

Antes de cerrar esta sección, conviene recordar que lo que hemos analizado se refiere a los incentivos que, en principio, deberían de generar la participación o la confianza para que estén presentes robustas expectativas de colaboración. En ese ámbito, el análisis nos permite llegar a dos conclusiones parciales pero igualmente importantes. La primera es que los incentivos que las dos variables producen no son homogéneos y que, en ese marco, la confianza tiene un efecto más intenso para favorecer la cooperación que la participación o el estar asociado. Esa además, tiende a motivar diferenciadamente las expectativas según se trate de un compromiso firme - flexible de colaboración, mientras que la confianza reduce esa diferencia sin suprimirla. La segunda consideración establece que ambas variables pueden ser moduladas en su capacidad de incentivar comportamientos por factores de orden distinto: por densidad asociativa, contextos cívicos culturales o institucionales. Por lo demás, la cultura está concretizada en pautas y normas formalizadas o no.

\section{Participación, confianza y colaboración específica con el gobierno}

En esta sección se analizan las expectativas de colaboración específica con el gobierno. Decimos específica porque las expectativas están medidas a partir de la posibilidad de una cooperación en algo concreto. No se trata por tanto de una disposición totalmente abierta y anticipada como en algunos casos puede ser la legitimidad. Hemos asumido que la expectativa de un comportamiento cooperativo, aunque sea específico, refleja la valoración de con quien se colabora. Consideramos ahora si la participación y la confianza tienen el mismo efecto de "incentivo" en la

partes la política está jerárquicamente organizada y más centrada en la ventaja personal" (PUTNAM, 1994, p. 117). 
MILLÁN, R. Confianza y paticipación en México....

conformación de expectativas generalizadas de cooperación con el gobierno que entre las personas, según hemos visto. La distribución agregada de la participación es la siguiente:

Cuadro 4

Expectativas de colaboración con el gobierno y participación (\%)

\begin{tabular}{|l|c|c|c|c|c|c|c|c|c|c|c|c|}
\hline \multirow{2}{*}{$\begin{array}{l}\text { Nivel de } \\
\text { expectativas }\end{array}$} & \multicolumn{4}{|c|}{ General } & \multicolumn{3}{|c|}{ Chilpancingo } & \multicolumn{4}{c|}{ Saltillo } & \multicolumn{3}{c|}{ Monterrey } \\
\cline { 2 - 14 } & 0 & $\begin{array}{c}\text { De } \\
1 \text { a 2 }\end{array}$ & $\begin{array}{c}3 \\
\text { o más }\end{array}$ & 0 & $\begin{array}{c}\text { De } \\
1 \text { a 2 }\end{array}$ & $\begin{array}{c}3 \\
\text { o más }\end{array}$ & $\begin{array}{c}\text { De } \\
1 \text { a 2 }\end{array}$ & $\begin{array}{c}3 \\
\text { o más }\end{array}$ & $\begin{array}{c}\text { De } \\
1 \text { a 2 }\end{array}$ & $\begin{array}{c}3 \\
\text { o más }\end{array}$ \\
\hline Todos & 22,1 & 22,5 & 25,3 & 23,9 & 23,9 & 27,2 & 19,7 & 23,2 & 19,5 & 22,9 & 21,9 & 29,2 \\
\hline La mayoría & 41,6 & 41,4 & 39,1 & 38,5 & 37 & 34,8 & 43,3 & 39,3 & 45,3 & 41,3 & 43,6 & 36,5 \\
\hline Algunos & 33 & 33,5 & 33,8 & 33,9 & 36,1 & 36,4 & 33,4 & 34,8 & 34,8 & 32,8 & 32,2 & 31 \\
\hline Ninguno & 3,2 & 2,6 & 1,8 & 3,8 & 3 & 1,6 & 3,6 & 2,8 & 0,4 & 3 & 2,3 & 3,2 \\
\hline
\end{tabular}

Como se aprecia, gruesamente no se da un una relación consistente entre participación asociativa y expectativa de cooperación específica con el gobierno. De hecho, esta últimas son muy semejantes, en el Cuadro general, entre los que están o no asociados, por lo que mantener esa calidad no parece hacer alguna diferencia respecto de la disposición con el gobierno. El mismo comportamiento aparece al considerar los resultados por municipio. En consecuencia, sea en términos de tendencia general o considerando la particularidad de cada comunidad, la experiencia asociativa, por sí misma y pese a su densidad o número, no estimula en mayor medida la expectativa de cooperación con el gobierno. Al asumir esto, es inevitable constatar que ambas variables se comportan independientemente. Es decir, la pertenencia a asociaciones cívicas, y la previsible confianza y expectativas que dichas interacciones generan, no parece transitar de esos grupos a un ámbito público más amplio, al menos no bajo la forma de disposición con el gobierno. Esa relación se manifiesta tanto en términos de intensidad como de extensión, de expectativa de un compromiso selectivo o no selectivo. El dato contrasta con algunas afirmaciones. "Las asociaciones civiles contribuyen - ha dicho Putnam (1994, p. 110) - a la eficiencia y estabilidad del gobierno democrático, tanto por su efectos "internos" sobre los miembros individuales como por sus efectos "externos" sobre el estado". Los efectos "internos" son la cooperación, la solidaridad y el espíritu público. En el espacio de las tres comunidades estudiadas, si ese paso se da, de manera que - como quiere la teoría - la participación en asociaciones cívicas propicie la colaboración y eficiencia del gobierno, ocurre en la medida en que aquella incorpora, interna o contextualmente, otros elementos y no sólo por sí misma. 
Un Cuadro radicalmente distinto aparece cuando tomamos en cuenta la confianza. Los datos se revelan extraordinariamente consistentes con los supuestos teóricos. En términos generales, y en cada uno de los casos, los que tienen confianza tienen también una mayor expectativa de cooperación con el gobierno tanto en el total como mayoritariamente generalizado. Además, entre los que no confían la baja disposición a colaborar es consistentemente mayor. Los datos fincan un comportamiento muy semejante de la confianza con las expectativas de cooperación tanto entre personas como con el gobierno. En general, podría aseverarse que la confianza interpersonal se "traduce" en un grado significativo en efectiva disposición para colaborar en el ámbito público, y en particular con el gobierno. (Cuadro 5)

\section{Cuadro 5}

Expectativas de cooperación con el gobierno y confianza interpersonal (\%)

\begin{tabular}{|c|c|c|c|c|c|c|c|c|}
\hline \multirow{2}{*}{$\begin{array}{l}\text { Nivel de } \\
\text { expectativas }\end{array}$} & \multicolumn{2}{|c|}{ General } & \multicolumn{2}{|c|}{ Chilpancingo } & \multicolumn{2}{|c|}{ Saltillo } & \multicolumn{2}{|c|}{ Monterrey } \\
\hline & Confía & No confía & Confía & No confía & Confía & No confía & Confía & No confía \\
\hline Todos & 28,1 & 19,1 & 30,3 & 16,8 & 28,9 & 16,6 & 27,3 & 20,5 \\
\hline La mayoría & 43,6 & 40,1 & 43,8 & 30,4 & 41,4 & 42,3 & 44,5 & 40 \\
\hline Algunos & 26,2 & 37,4 & 23 & 49,4 & 27,5 & 37,4 & 26,3 & 36,2 \\
\hline Ninguno & 2,2 & 3,4 & 2,9 & 3,4 & 2,3 & 3,7 & 2 & 3,3 \\
\hline
\end{tabular}

Importa en esa línea indicar que en el caso de contraste (Chilpancingo) la relación positiva entre ambas variables es - sorprendentemente - más fuerte que en los otros dos pese a su características cívicas y de desarrollo social. Con ello, se abona terreno para afirmar la tesis del papel de la autoridad y la cultura cívica que hemos apenas discutido en función de la confianza interpersonal (Cuadro 3). Esas características parecen, de nuevo, tener una función de modulación; en este caso facilitan "afinar", profundizar, el vínculo entre confianza y disposición al gobierno en un contexto donde aquella produce, comparativamente, un incentivo bajo en la espera de posibles acciones colectivas y coordinadas horizontalmente (tal y como vimos). Atendible es entonces la proposición de que a mayor solvencia cívica, democrática y económica, más modulada está la relación entre confianza y cooperación pública, sin que ello signifique, en ningún caso, que la conexión no persista. Sólo se reitera que los elementos contextuales, entre los que destacan la cuestión cívica y los arreglos institucionales, hacen variar como, dijimos apenas, la extensión con que la confianza impulsa la colaboración pública. 
De cualquier manera, la confianza resulta ser en toda condición un mejor estímulo a la disposición al ámbito público y para coordinar acciones con el gobierno que la participación en asociaciones cívicas como tal. En este sentido, quizás Ostrom y Ahn (2003) tengan razón cuando señalan que el papel de la participación cívica y de las redes "no consiste simplemente en proporcionar incentivos adicionales a las personas egoístas para que se comporten de manera cooperativa. Como señala Putnam, las redes densas de intercambio social son condición crucial para el surgimiento de normas de reciprocidad generalizada" (2003, p. 189). La reciprocidad entonces se constituye en un factor importante y como se sabe está teóricamente asociada a la confianza y a normas que regulan las interacciones. Pero debe ser claro que la confianza deriva de factores contextuales diversos y en consecuencia está en posibilidad de incentivar la cooperación pública como un factor no derivado o restringido a la actividad en asociaciones cívicas. Los arreglos institucionales, las instituciones son factores que reducen contingencia, acotan riesgos y solventan socialmente confianza en las interacciones y los intercambios ${ }^{17}$. Es decir, facilitan cooperación aunque de modo imperfecto. De ahí su importancia para el capital social; y la de éste, frente a ellas.

\section{Participación, confianza y cooperación efectiva}

Nos preguntamos ahora sobre factores que pueden modular las relaciones que hemos visto entre esas tres variables. En particular nos interesa determinar si la experiencia "de una cooperación efectiva"18, si el hecho de haber realmente colaborado con los otros para la consecución de un determinado fin, está igualmente asociado a la participación y a la confianza que la expectativa de cooperación. Queremos saber si entre la experiencia y la cooperación hay alguna diferencia con relación a las otras variables porque eso nos dará una pista a propósito de que tanto esta última es un elemento simplemente "derivado" de aquellas dos variables, o si también las modifica. Se trata, en resumen, de identificar si la cooperación efectiva modula o no el "vínculo virtuoso" de los elementos del capital social sea en términos positivos o negativos.

\footnotetext{
17 "Las instituciones existen y reducen las incertidumbres propias de la interacción humana...Es suficiente decir aquí que las incertidumbres se deben a información incompleta con respecto de la conducta de otros individuos en el proceso de interacción humana" (NORTH, 1990, p. 41).

18 La pregunta utilizada para medir cooperación efectiva fue: "En el último año $i$ ha trabajado con otros vecinos para hacer algo en beneficio de su colonia?.
} 
Gráfica 1

Nivel de cooperación y número de membresías en asociaciones formales (\%)

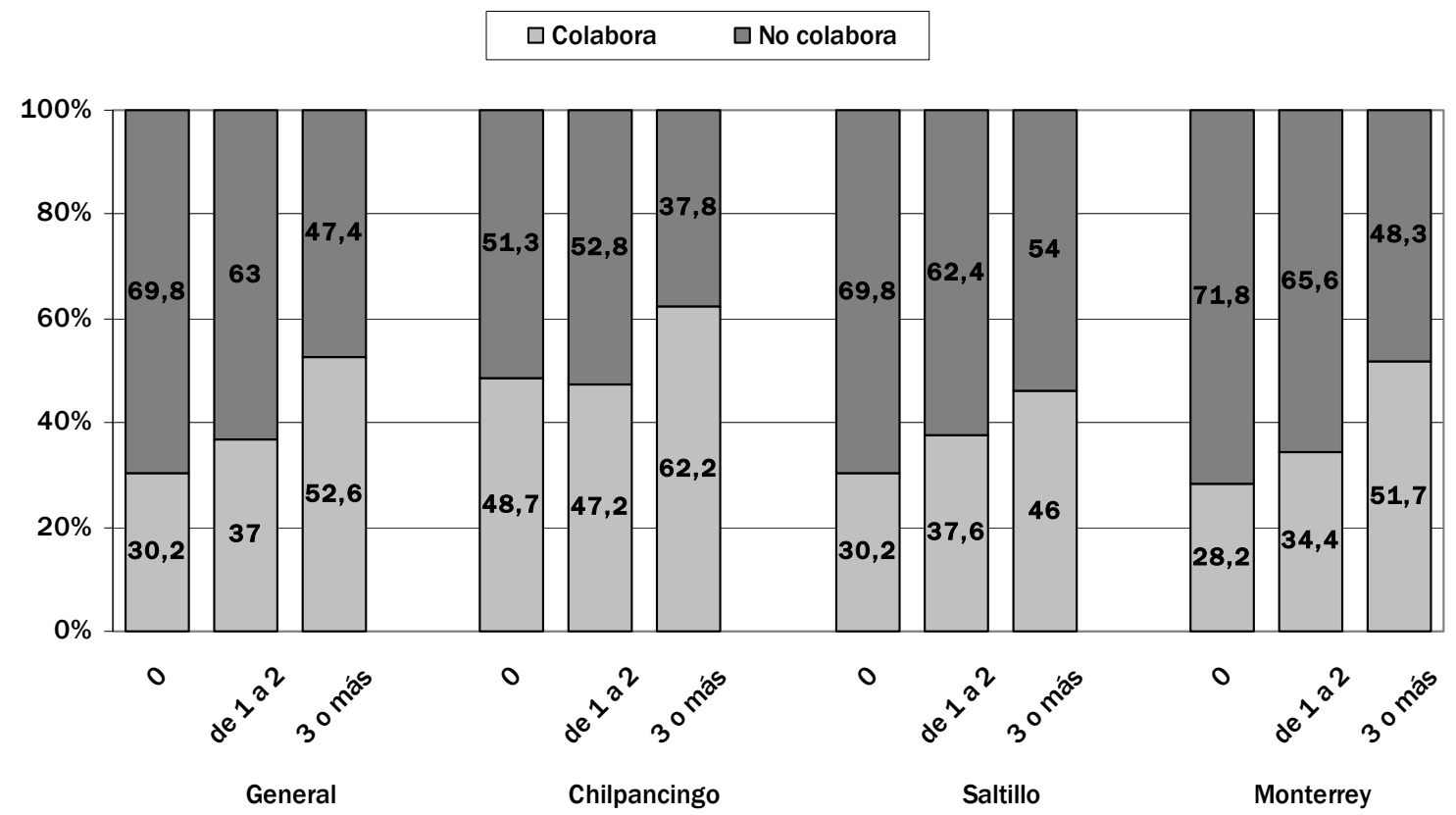

En general, se verifica que los individuos que han colaborado efectivamente en algún tipo de acción colectiva tienden a participar más en asociaciones. Gruesamente el mismo comportamiento se da en cada uno de los municipios. Por tanto, la relación positiva entre participación asociativa y cooperación tiende a conformarse de manera más fuerte que cuando se trata sólo de expectativas. El caso de contraste (Chilpancingo) presenta una tendencia ligeramente distinta a la de los otros (entre no participar y hacerlo una vez). Sin embargo, gruesamente se observa un comportamiento entre variables prácticamente lineal: a más colaboración efectiva, más participación en asociaciones. El relación entre densidad asociativa y cooperación que parecía darse de manera independiente respecto de las expectativas, se da aquí en forma directa. El efecto modulante de la experiencia de colaboración es innegable. 


\section{Gráfica 2}

\section{Cooperación efectiva y confianza interpersonal (\%)}

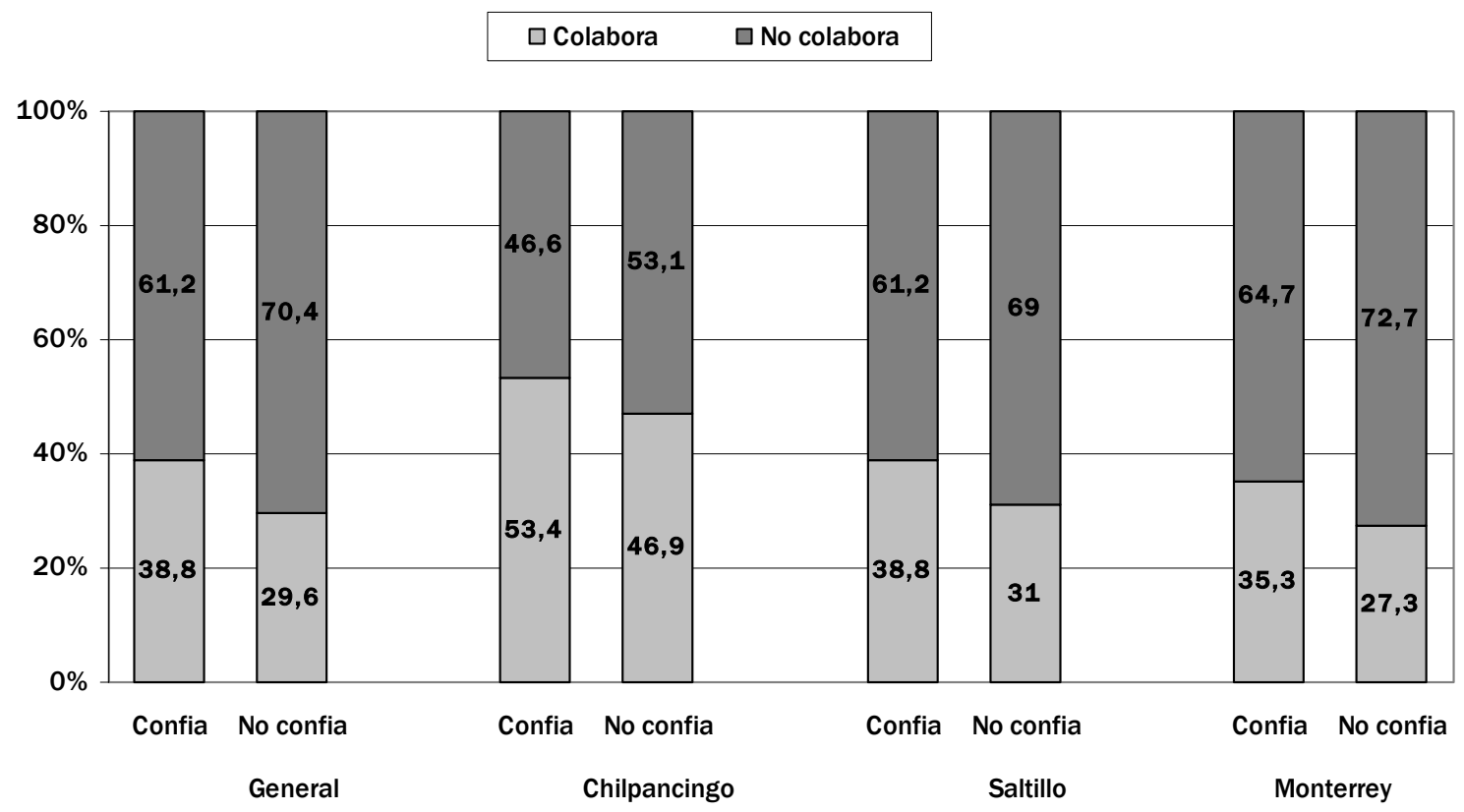

Nuevamente en la Gráfica 2 se confirma, en lo general y por municipios, que los individuos que tienen confianza cooperan sostenidamente más que los que no la tienen. No obstante, destaca el hecho de que esa proporción es ligeramente menor que la que vimos que se estableció con relación a la participación en la Gráfica 1 anterior. En este punto se encuentra, creemos, una capacidad importante del pertenecer a asociaciones. Razonablemente, la pertenencia a asociaciones dota de oportunidades efectivas de colaboración y facilita adquirir un "conocimiento del cooperar" más acusado que el que la mera confianza, sin ningún soporte organizativo, puede ofrecer. Las asociaciones constituyen de facto instituciones cuyos diseños implican normas formalizadas e informales que estructuran patrones de comportamiento y reciprocidad. Las normas pueden facilitar o inhibir la cooperación (KNIGHT, 2001; OSTROM y AHN, 2003). En términos típicos, las asociaciones representan consecuentemente arreglos institucionales que dotan de posibilidades de cooperación y de gestión de pautas reciprocas, si bien es prudente suponer que tanto las "oportunidades" como los "ejercicios" tienen un impacto diferenciado en los niveles de confianza y en las expectativas generalizadas de cooperación. Quizás, esa "disponibilidad práctica" module las "expectativas" de 
colaboración que mayoritariamente ofrece, en principio, la confianza. De hecho, es justo en la idea de que los "arreglos organizacionales" se traslapan y por ello se extienden a escalas mayores, transfiriendo saberes y reglas de uso útiles, en que Ostrom (2000) basa su tesis de que tales experiencias pueden ayudar a los individuos a resolver problemas de acción colectiva. $Y$ es también en esa idea de que las asociaciones se traslapan que Putnam finca su tesis de la importancia de dichas organizaciones para la gobernabilidad democrática; el paso de normas de reciprocidad a cultura cívica.

En cualquier caso, la Gráfica 2 nos indica que es innegable que los que confían en los otros cooperan más. Interesante resulta en ese sentido que si nos detenemos en el caso de contraste (Chilpancingo) se revelan, de nuevo, dos cosas en cierto punto incomodas. En primer lugar, proporcionalmente es en esa sociedad donde "más" se han colaborado; en segundo, es notable que incluso los que no confían han tenido mayores experiencias de cooperación que las que han desarrollado los que si confían en los otros dos casos. El hecho de que su proporción sea considerablemente alta plantean el problema de qué factores producen este "sobre efecto" en los incentivos de la cooperación. Inmediatamente se antoja contestar (como en parte lo hicimos antes) que es consecuencia de una cultura comunitaria, con requerimientos asociativos relativamente obligatorios y con procesos de individualización menos acentuados y por tanto una reducida presencia de ámbitos electivos (GERMANI, 1981). La idea parece afirmarse si se repara que el Cuadro muestra que la relación entre cooperación efectiva y confianza es más intensa mientras menos sólidos económicamente son los contextos municipales y registran más marginalidad. Pero la respuesta así considerada discrepa de la tesis que postula la relación entre cultura cívica y confianza; aunque abre espacio para afirmar la noción de "confiabilidad" como fenómeno que facilita intercambios (HARDíN, 2001).

En efecto, en contextos altamente asociativos y de pobreza como es el caso de contraste (Chilpancingo), la pertenencia y la colaboración pueden retribuir en términos de "coberturas" y de rentabilidades diversas ante situaciones de mayor premura. Ya Olson (1965) estableció que la naturaleza del "bien" que propicia la acción colectiva también puede modularla ${ }^{19}$. Si se asumen estas posibles explicaciones, habría que reconocer - de nuevo - que la "cultura cívica", como condensación de capital social (Putnam), no es una función exclusiva de la confianza y ni de la presencia extendida de la cooperación. Aunque claramente no se contraponen, no se requieren obligatoriamente con la misma determinación: la confianza y la cooperación aparecen como independientes de la cultura cívica. Un problema distinto es la medida en que los beneficios de la cooperación se generalizan

\footnotetext{
19 "La evidencia sugiere que son muy pocos los individuos que son altruistas incondicionales decididos a cooperar o confiar en los demás sin que nada más importe." (OSTROM y AHN, 2003, p. 186).
} 
públicamente, cuestión a la que sí parece estar más asociada la cultura cívica y los contextos democráticos. Dado que la Gráfica sugiere que en condiciones de mejor desarrollo socioeconómico y de una cultura cívica más afirmada, la asociación entre confianza y cooperación está más mediada, o es menos firme, cabría preguntarse si no son precisamente esos contextos, cultural e institucionalmente formados, los que dan un signo positivo a esa mediación.

\section{Gráfica 3}

Nivel de expectativas y cooperación efectiva (\%)

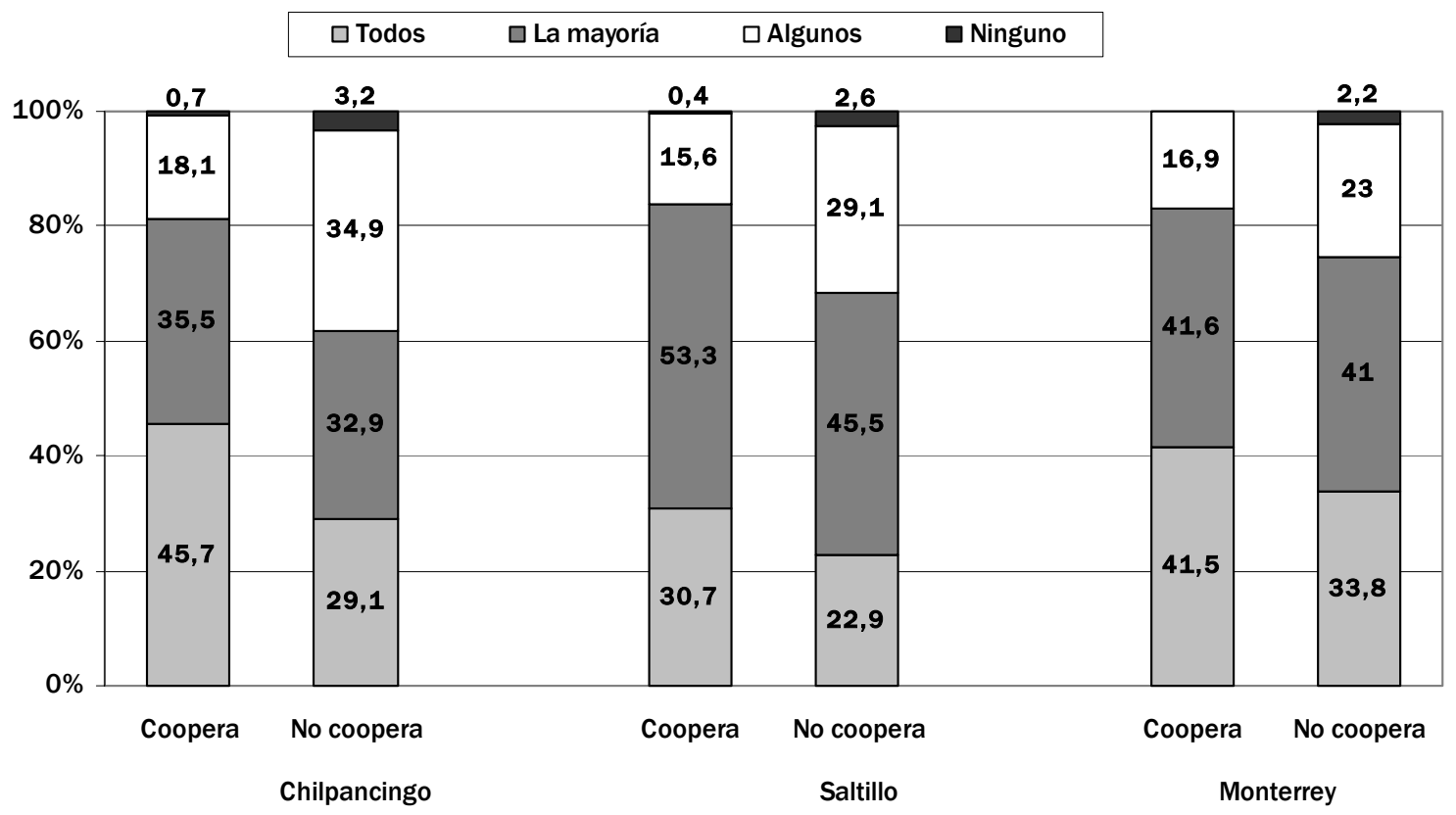

Igualmente interesante es la cuestión de la conformación de expectativas de cooperación. En todos los casos, sin ninguna excepción, los individuos que han efectivamente colaborado tienen proporciones más altas en las expectativas generalizadas de cooperación. Resulta claro que la experiencia efectiva las incentiva fuertemente. Su comportamiento en relación con ellas es, de hecho, semejante al que observamos con respecto a la confianza (Cuadro 3). El dato, sin embargo, es que la cooperación efectiva parece incrementar, en términos gruesos, la proporción de las expectativas totalmente generalizadas; esto es, la intensidad del compromiso esperado y su tipo: firme-no selectivo. Pero si suman, como dijimos anteriormente, las expectativas total y mayoritariamente generalizadas su proporción es semejante 
a la que se tiene con la confianza. En consecuencia, la cooperación efectiva "aceita" la intensidad del compromiso (como lo hemos definido) pero no "extiende" socialmente la disposición a colaborar más que la confianza, la cual tiene también sus límites. La experiencia de colaboración efectiva si puede modular, por el carácter no selectivo del compromiso que impulsa, el horizonte de los "agentes" con quienes se estaría dispuesto a cooperar. En ese caso, puede modular la disposición con el gobierno.

\section{Gráfica 4}

Nivel de expectativas de cooperación con el gobierno y cooperación efectiva (\%)

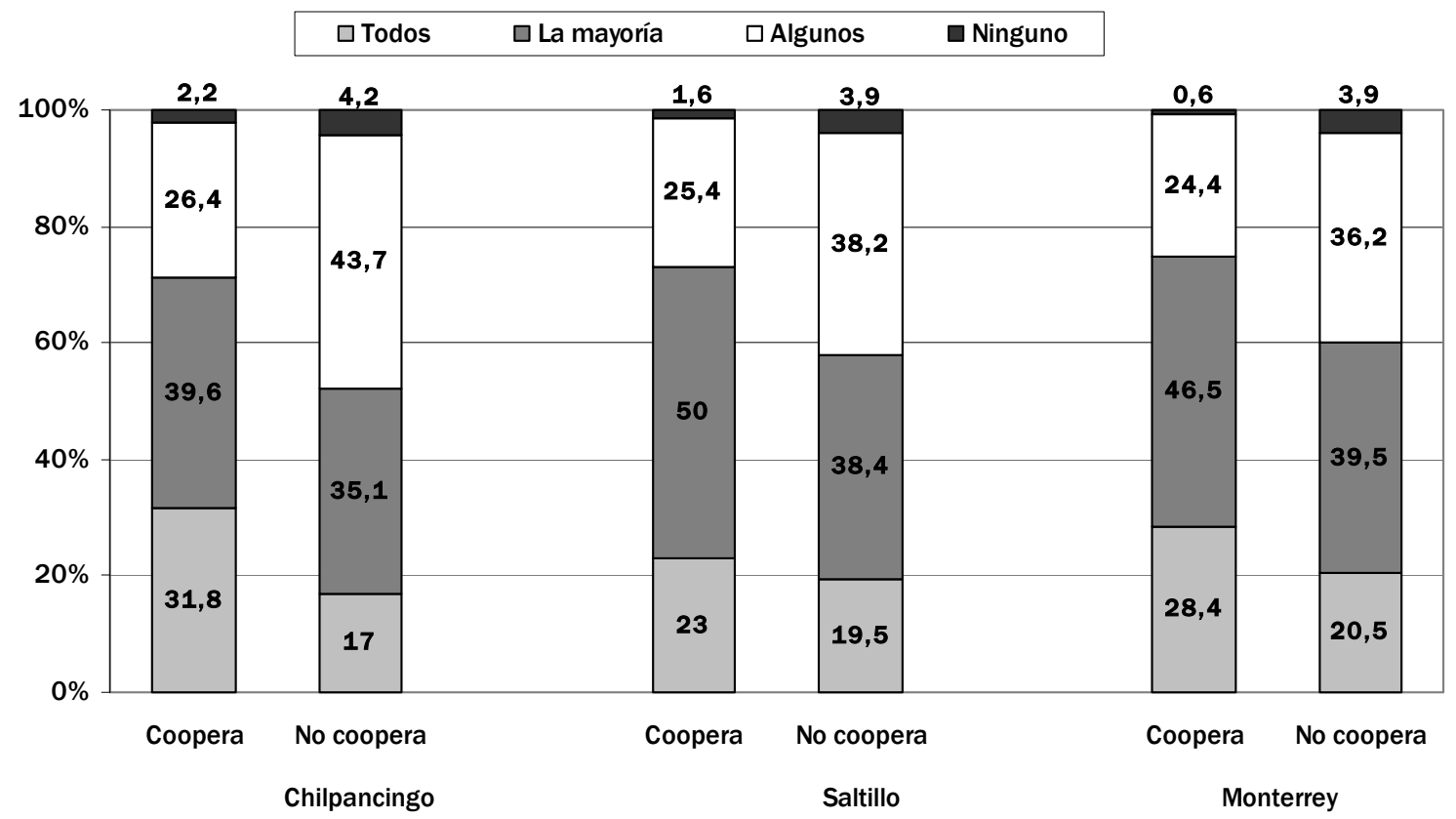

De manera muy nítida se aprecia que los que han tenido experiencia efectiva de colaboración mantienen expectativas generalizadas de cooperación con el gobierno notablemente más altas que los otros. Ella "modula" - casi radicalmente esas expectativas. Como se recuerda (Cuadro 5) la confianza actuaba como incentivo más sólido en la previsible disposición hacia el gobierno que la participación. Al mismo tiempo, ese incentivo se expresaba en proporciones ligeramente menores que las que registraban las expectativas de colaboración entre individuos (Cuadro 3). A su vez, esas expectativas son levemente más altas que las 
que se dan entre la experiencia de cooperación y colaboración con el gobierno (Gráfica 4). Pero también son ligeramente más bajas que las que se establecen entre experiencia efectiva y disposición para colaborar entre personas (Gráfica 3). En consecuencia, puede ser atendible la tesis de que la experiencia efectiva modula la eficacia del incentivo a la cooperación que la confianza finca, tanto entre las personas como con la institución pública o el gobierno. Todo, si consideran conjuntamente las expectativas total y mayoritariamente generalizadas.

En este sentido, es interesante recordar que en la relación cooperaciónconfianza, el caso de contraste (Chilpancingo) tiene el valor más bajo (Cuadro 3), pero ese mismo caso muestra el valor más alto en relación con las posibilidades de cooperación con el gobierno (Cuadro 5), lo que de nuevo nos ofrece una duda en términos de algunos supuestos teóricos del capital social - que en parte ya han sido atendidos. Comparativamente con los otros casos, en el de contraste esos supuestos parecerían correr en sentido contrario: a menos disposición de cooperar entre personas mas disposición para hacerlo con el gobierno. Inversamente, la experiencia efectiva "ajusta" de una forma más convincente las consideraciones teóricas. De hecho, como se observa (Gráficas 3 y 4) los casos que no son de contraste (Saltillo y Monterrey) tienen valores más altos en la cooperación interpersonal y también en la disposición frente al gobierno. Por lo demás es claro que, comparativamente, esos municipios tienen una cultura cívica más afirmada, en particular uno de ellos (Monterrey). Se podría decir que mientras que en aquellas comunidades que son más sólidas, económica, cívica y en términos de integración social, es más efectivo el incentivo de la confianza para la cooperación si se parte de una experiencia efectiva. Esto significa, si la confianza es reforzada bajo la experiencia de cooperación. Esto es, que ambas se refuerzan mutuamente.

Confianza y cooperación: evaluación del gobierno

A efecto de contrastar el argumento anterior es conveniente considerar la evaluación del gobierno. Según el informe latinoamericano sobre participación ciudadana (2005), en todos los países de la región se registra que la cercanía con valores democráticos o la satisfacción con el desempeño del gobierno favorecen que los niveles de participación, de colaboración pública se incrementen notablemente. Del mismo modo, los supuestos del capital social han establecido que existe una asociación entre la confianza, la posibilidad social de la cooperación y el desempeño del gobierno y su valoración. A la luz de los resultados anteriores, esperaríamos cierta tendencia positiva entre esas variables. Veamos tres Cuadros muy brevemente. 


\section{Cuadro 6}

Evaluación del gobierno y Confianza (\%)

\begin{tabular}{|l|c|c|c|c|c|c|}
\hline \multirow{2}{*}{ Evaluación del desempeño de Gobierno } & \multicolumn{2}{|c|}{ Chilpancingo } & \multicolumn{2}{c|}{ Saltillo } & \multicolumn{2}{c|}{ Monterrey } \\
\cline { 2 - 7 } & Confía No confía & Confía & No confía & \multicolumn{2}{c|}{ Confía No confía } \\
\hline $\begin{array}{l}\text { El gobierno atiende los problemas de la } \\
\text { gente }\end{array}$ & 22,3 & 19,2 & 33,8 & 24,9 & 29,7 & 19,2 \\
\hline $\begin{array}{l}\text { El desempeño del gobierno local es } \\
\text { bueno o muy bueno }\end{array}$ & 25,6 & 20,7 & 41,2 & 40,8 & 35,1 & 30,5 \\
\hline $\begin{array}{l}\text { El gobierno toma en cuenta la opinión } \\
\text { de los ciudadanos }\end{array}$ & 29,1 & 24,2 & 54,5 & 49,6 & 54,8 & 40,5 \\
\hline $\begin{array}{l}\text { Las autoridades locales dan un trato } \\
\text { justo a los ciudadanos }\end{array}$ & 11,3 & 7,7 & 23,5 & 13,6 & 19,8 & 14,3 \\
\hline
\end{tabular}

En los tres municipios, la evaluación positiva del gobierno, en todos lo rubros, es más alta entre quienes confían. Además, resalta el dato que estos evalúan mejor su calidad de ciudadanos y su capacidad de influir en las decisiones públicas. Al mismo tiempo, esa asociación positiva tiene valores considerablemente altos en los casos cuyas sociedades son más sólidas económicamente, mejor integradas y apoyadas en patrones de relación más democráticos.

Cuadro 7

Evaluación y expectativas de cooperación (\%)

\begin{tabular}{|l|c|c|c|c|c|c|}
\cline { 2 - 7 } \multicolumn{1}{c|}{} & \multicolumn{6}{c|}{ Expectativas de Cooperación } \\
\hline \multirow{2}{*}{ Evaluación del desempeño de Gobierno } & \multicolumn{2}{c|}{ Chilpancingo } & \multicolumn{2}{c|}{ Saltillo } & \multicolumn{2}{c|}{ Monterrey } \\
\cline { 2 - 7 } & Sí & No & Sí & No & Sí & No \\
\hline $\begin{array}{l}\text { El gobierno atiende los problemas de la } \\
\text { gente }\end{array}$ & 23,3 & 15,6 & 30,2 & 23,4 & 24,9 & 17,2 \\
\hline $\begin{array}{l}\text { El desempeño del gobierno local es } \\
\text { bueno o muy bueno }\end{array}$ & 25,5 & 17,7 & 43,6 & 35 & 35,8 & 25,4 \\
\hline $\begin{array}{l}\text { El gobierno toma en cuenta la opinión } \\
\text { de los ciudadanos }\end{array}$ & 30,5 & 19,3 & 53,8 & 45,9 & 49,5 & 37,1 \\
\hline $\begin{array}{l}\text { Las autoridades locales dan un trato } \\
\text { justo a los ciudadanos }\end{array}$ & 10 & 9 & 18,4 & 12,7 & 20,3 & 9,5 \\
\hline
\end{tabular}


MILLÁN, R. Confianza y paticipación en México....

El mismo comportamiento priva en relación con las expectativas de cooperación: quien las tiene hace mejor evaluación de su gobierno y, en términos generales, ese se ubica en una sociedad que se desempeña mejor socialmente que el caso de contraste (Chilpancingo). En ese contexto, es notable el dato de que quien tiene expectativas de colaboración con los otros, se asume más firmemente como ciudadano y hace una evaluación positiva del rubro específico de desempeño de gobierno. La diferencia en este rubro con el caso de contraste es notable.

Cuadro 8

Evaluación y cooperación efectiva (\%)

\begin{tabular}{|l|c|c|c|c|c|c|}
\hline \multirow{2}{*}{$\begin{array}{l}\text { Evaluación del desempeño de } \\
\text { Gobierno }\end{array}$} & \multicolumn{2}{|c|}{ Chilpancingo } & \multicolumn{2}{c|}{ Saltillo } & \multicolumn{2}{c|}{ Monterrey } \\
\cline { 2 - 7 } & Coopera & $\begin{array}{c}\text { No } \\
\text { coopera }\end{array}$ & Coopera & $\begin{array}{c}\text { No } \\
\text { coopera }\end{array}$ & Coopera & $\begin{array}{c}\text { No } \\
\text { coopera }\end{array}$ \\
\hline $\begin{array}{l}\text { El gobierno atiende los problemas de } \\
\text { la gente }\end{array}$ & 23,3 & 18 & 32,2 & 26 & 28 & 19,9 \\
\hline $\begin{array}{l}\text { El desempeño del gobierno local es } \\
\text { bueno o muy bueno }\end{array}$ & 24,1 & 22,7 & 51,2 & 35,5 & 37,5 & 30,4 \\
\hline $\begin{array}{l}\text { El gobierno toma en cuenta la opinión } \\
\text { de los ciudadanos }\end{array}$ & 25,5 & 28,1 & 68 & 47,9 & 49,1 & 43,8 \\
\hline $\begin{array}{l}\text { Las autoridades locales dan un trato } \\
\text { justo a los ciudadanos }\end{array}$ & 11,5 & 7,5 & 18,9 & 15,6 & 21 & 14,6 \\
\hline
\end{tabular}

La cooperación efectiva, su experiencia, no sólo se comporta conforme a las otras variables en cuanto a la evaluación del gobierno, sino que relativamente acentúa la relación positiva. Esto es particularmente cierto en el rubro específico de desempeño del gobierno local. De nuevo, parece plausible asumir que la experiencia efectiva profundiza (así sea ligeramente) el efecto de incentivo de la confianza y de la disposición a cooperar. Está vinculada a un sentido comparativamente fuerte de ciudadanía. Por lo demás, sus valores son más altos que los que se aprecian entre evaluación del gobierno, confianza o expectativas. Lo son si se prescinde del caso de contraste (Chilpancingo). Sólo allí los valores son semejantes en las tres variables: confianza, expectativas y cooperación efectiva tienen prácticamente el mismo comportamiento para la evaluación del desempeño del gobierno en esa comunidad. Sólo allí la cooperación efectiva no parece generar algún incentivo adicional. Además, en todas las variables se registran los valores más bajos en comparación con los otros casos. Esto es consistente con el hecho de que, como señalamos, tiene la relación más débil entre confianza y expectativas de cooperación entre la gente (Cuadro 3), pero es absolutamente inconsistente con el hecho de que tiene la relación más fuerte entre confianza y expectativas de 
cooperación con el gobierno (Cuadro 5). Al desconcierto, se antepone, de nuevo, alguna precisión.

En primer lugar, es claro que los otros municipios, con sus características, muestran más coherencia entre niveles de confianza y cooperación pública, incluida la colaboración con el gobierno y su valoración. Esto presupone que en el caso de contraste (Chilpancingo) algunos factores, previsiblemente, "externos" a los componentes del capital social, no permiten que la confianza se trasfiera como valoración positiva al gobierno pese a tener valores altos en las expectativas y experiencias de colaboración con él. En algún sentido, esa ambivalencia podría significar que los beneficios de esa cooperación no se generalizan públicamente en la proporción esperada y la evaluación del gobierno, ni la confianza interpersonal. Por ello, quizás sería más apropiado asumir que en este caso la confianza opera bajo la forma de confidence en tanto que, como indicamos, facilita el intercambio, incluso porque reduce opciones. La confiabilidad explicaría tentativamente porque se da la presencia de baja confianza interpersonal, alta expectativa de cooperación con el gobierno pero baja evaluación del mismo. Ciertamente, esa "forma" de confianza refiere a modulaciones "internas" de los elementos del capital social.

No resultaría entonces apresurado reforzar, finalmente, la idea de que arreglos institucionales de esa sociedad inhiben la cooperación entre individuos sin intervención pública y que esos arreglos están relacionados con formas concretas que toma el capital social o la confianza. A su vez, eso permitiría suponer que la extensión, la generalización, de los beneficios públicos de la confianza y la cooperación deben corresponderse con instituciones y "culturas" democráticas, tal y como la teoría ha sostenido. Por ello no es desatinado asumir que los componentes del capital social, en especial la confianza en sus formas y la presencia entendida de la cooperación, no es función exclusiva de la "cultura cívica". Los contextos institucionales, sus arreglos, la manera en que favorecen la cooperación y extensión pública de sus beneficios, también parecen importar.

\section{Consideraciones finales}

Nos preguntamos, al inicio, si la cooperación debería ser considerada como un elemento "derivado" estrictamente de los componentes del capital social. Principalmente, distinguimos entre expectativa de cooperación y experiencia efectiva a efecto de poder determinar si su comportamiento era semejante en relación a la confianza, la participación y la evaluación del gobierno. Entendimos que esa diferencia nos permitiría tener alguna señal sobre el estatuto de la cooperación y abordar algunas preguntas para el contexto de los tres municipios estudiados. Esas preguntas se referían a si la confianza o la participación se 
"trasfieren" sin modalidad como incentivos de colaboración social y si constituían factores de evaluación de los gobiernos. Ciertamente, el análisis no nos permite llegar a conclusiones definitivas pero si abre algunos puntos de reflexión que son indicativos de aspectos interesantes en el caso de las tres comunidades estudiadas. Concretamente esos son los siguientes.

La confianza y la participación en asociaciones tiene un comportamiento heterogéneo respecto de su capacidad para incentivar expectativas de cooperación. El efecto de la primera es más fuerte sobre está ultima. En particular, destaca que la participación, a diferencia de la confianza, incentiva diferenciadamente la intensidad y la extensión de las expectativas de la cooperación. Además, su relación con ésa está modulada por la densidad asociativa. Tampoco su relación con la confianza es lineal: no todo el que la tiene participa o se asocia, aunque el que lo hace la propicia.

Del mismo modo, ambas variables se comportan diversamente con respecto a la expectativa de colaboración con el gobierno. No se da una relación consistente entre cooperación pública con intervención del gobierno y participación. En contraste, si hay una relación consistente con la confianza en términos generales. Pero el incentivo positivo a la cooperación pública aparece modulado por factores que implican solvencia cívica y arreglos institucionales y democráticos.

El "vinculo virtuoso" entre participación, confianza y cooperación se afirma notablemente cuando se relacionan con la experiencia efectiva de colaboración. Esto implica que esa última variable no puede ser considerada como un elemento derivado sino que influye y es influido. En particular destaca que la confianza al asociarse a ella se muestra significativamente modulada en su forma. El carácter comunitario y cívico de la cultura, así como los arreglos institucional y el desarrollo económico están, a su vez, asociados a la forma que toma la confianza, si como tal o como confidence.

Bajo las regulaciones anteriores, la confianza y la participación son dos dimensiones centrales de la cooperación, y estas tres variables del aprecio por los gobiernos, de su evaluación. Su relación es estrecha. Pero encuentra de nuevo modulaciones porque los componentes del capital social no aparecen, en el contexto de estudio, como exclusivos de un marco cultural. Más precisamente: la participación en asociaciones, la confianza y la extensión de la cooperación no son función exclusiva de la cultura cívica y de contextos de desarrollo económico. Al parecer esa facilita la generalización de beneficios producidos por esas variables. Pero no lo hace sola: los arreglos institucionales, particularmente de orden democrático, parecen tener un peso considerable. En consecuencia, tanto una como los otros afectan los posibles incentivos del capital social en la evaluación positiva de los gobiernos. 


\section{Referencias Bibliograficas}

ATRIA, R. et al. Capital social y reducción de la pobreza en América Latina y el Caribe: en busca de un nuevo paradigma. Santiago de Chile: CEPAL-Michigan State University, 2003.

BREHM, J.; RAHN, W. Individual-level evidence for the causes and consequences of social capital. America Journal of Political Science, v. 41, n. 3, p. 999-1023, 1997.

COLEMAN, J. Foundations of Social Theory. Cambridge: The Belknap Press of Harvard University Press, 1990.

DASGUPTA, P. Trust as a commodity. In: GAMBETTA, D. (comp.). Trust: making and breaking cooperative relations. Oxford: Basil Blackwell, 1988.

DASGUPTA, P.; SERAGELDIN, I. (comps.). Social capital: a multifaceted perspective. Washington, DC: The Work Bank, 2000.

DE SOUZA Verschoore Filho, J. R. El capital social y los nuevos instrumentos de políticas públicas para el desarrollo sostenido: la experiencia de Rio Grande do Sul, Brasil. Reforma y Desarrollo, Caracas: CLAD, n. 17, junio 2000.

DURSTON, J. Construyendo capital social comunitario. Revista de la CEPAL, v. 69, diciembre 1999.

FOX, J.; GERSHMAN, J. The World Bank and social capital: lessons from ten rural development projects in the Philippines and Mexico. Policy Sciences, Netherlands, v. 33, n. 3 . 4, 2000.

GALLINO, L. Gli effetti dissociativi del processi associativi nella societá altamente diferénciate. In: ALBERONI, F. (et al.). La società industriale metropolitana e i problemi dell'area milanese. Milano: Franco Angeli, 1981.

GERMANI, G. Alcune considerazioni sulle cittá moderne e il loro futuro. In: ALBERONI, F. (et al). La società industriale metropolitana e i problemi dell'area milanese. Milano: Franco Angeli, 1981.

HARDIN, R. Conceptions and explanations of trust. In: COOK, K. Trust in society. New York: Rusell Sage Foundation, 2001. 
HEFFRON, J. M. Beyond community and society: the externalities of social capital building. Policy Sciences, Netherlands, v. 33, n. 3.4, 2000.

HOBSON, B.; LEWIS, J.; SIIM, B. Key concepts in gender European social politics. Cheltenham: Edward Elgar Press, 2001.

KNIGHT, J. Trust, norms, and the rule of law. In: COOK, K. Trust in society. New York: Cambridge University Press, 2001.

LOWNDES, V.; WILSON, D. Social capital and local governance: exploring the institutional design variable. Political Studies, Oxford, v. 49, n. 4, p. 629-647, 2001.

LUHMANN, N. Confianza. México: Universidad Iberoamericana/Anthropos, 1996.

LUNA, M.; VELASCO, J. L. Confianza y desempeño en las redes sociales. Revista Mexicana de Sociología, v. 1, México: IISUNAM, 2005.

MILLAN, R.; GORDÓN, S. Capital social: una lectura de tres perspectivas clásicas. Revista Mexicana de Sociología, México, v. 4, p. 711-747, 2004.

NORTH, D. C. Instituciones, cambio institucional y desempeño económico. México: FCE, 1993.

OLSON, M. The logic of collective action: public goods and the theory of groups. Cambridge, MA: Harvard University Press, 1965.

OSTROM, E. El gobierno de los bienes comunes: la evolución de las instituciones de la acción colectiva. México: UNAM/FCE, 2000.

OSTROM, E.; AHN, T. K. Una perspectiva de capital social desde las ciencias sociales: capital social y acción colectiva. Revista Mexicana de Sociología, México, v. 1, p. 155-233, 2003.

PUTNAM, R.; LEONARDI, R.; NANETTI, R. Y. Para que la democracia funcione. Tradiciones cívicas en Italia. Caracas: Galas, 1994.

SAMPSON, R.; RAUNDENBUSH, S.; EARLS, F. Neighborhoods and violent crime: a multilevel study of collective efficacy. Science, v. 227, n. 15, p. 918-924, august 1997. 
STOLLE, D. Clubs and congregations: the benefits of joining an association. In: COOK, K. Trust in society. New York: Russell Sage Foundation, 2001.

WOOLCOCK, M. Social capital and economic development: toward a theoretical synthesis and political framework. Theory and Society, v. 27, n. 2, p. 151-208, 1998.

Este artículo no hubiese sido posible sin la valiosa colaboración de Fiorella Mancini quien además de realizar los Cuadros hizo, como siempre, inteligentes y útiles comentarios.

Recebido e aprovado para publicação em julho de 2006. 